\title{
Driving Online Traffic by Using QR (Quick Response) Code
}

\author{
Harshini C $S^{1}$, Dr. Sathyanarayana $S^{2}$ \\ ${ }^{1}$ Research Scholar, Bangalore University, Bangalore \\ ${ }^{2}$ Professor, MP Birla Institute of Management, Race course road, Bangalore
}

\begin{abstract}
For many businesses, traditional print and publishing media (newspapers and magazines) remains one of the most important channels of marketing to consumers. Quick Response (QR) Code is a cost-effective marketing tool to engage consumers with online content and removes complexities of marketing messages. It is easy to generate, scan or print very easily and facilitate the user to get connected with messages, emails, SMS, websites etc. With marketers and advertisers increasingly using QR Codes in their promotion, consumers are also growing aware of what they are and how to scan them. QR Codes are used in different marketing formats such as business cards, print ads, coupons, product packaging and will bridge the gap between static traditional media and dynamic online content. Moreover, video based QR Codes works well with the print ads as it offers interactivity and comfort of seeking detailed information about the brands. The purpose of this study is to analyze how consumers use this tool to the maximum and take advantage with this innovative technology. These analytics would help the companies to assess the impact of their newspaper ad campaigns.
\end{abstract}

Keyword: Advertisements, Quick Response (QR) Codes, 2D codes, Newspaper, Online, Consumers

\section{Introduction}

QR Codes were first invented in 1994 by Japanese company Denso Wave Corporation for inventory management in the automobile industry. India is not far behind and codes are extensively used in transportation and management of product and product cartons. A QR Code is a 2D square shaped barcode that can store a lot of information, compared to a traditional barcode. It connects smartphone users to online content such as websites, videos, photo galleries and just about anything else on the web. The QR Code, placed on the newspaper ad, can be read by a QR Code scanning application on the smartphone. This will lead consumers directly to the desired content on the web, See product specifications, read reviews about products, register for an event or even make a purchase.

Brands such as State Bank of India, LG, Spykar, KAFF, Lavasa, Cox \& Kings, Symphony, Shoppers Stop, The Collective, DHFL, SimplyMarry, Advanced Hair Studio, Intec, Sikka Group, and Manyavar have used QR Codes in their newspaper advertisements to engage their readers with their online content. By using an advanced QR Code Management tool, these companies can tract scanning activity of their codes. They can track scans by date, city and device.

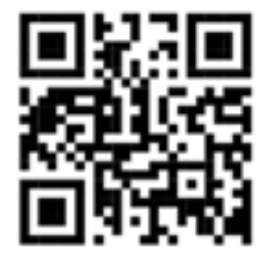

\section{Common uses of QR Codes in India}

Although widely popular in the West and in Asian countries such as Japan, Korea, and China, QR Codes are beginning to appear in India as well. A square shaped barcodes have been there around in India for more than two decades but only recently have seen entry into customer engagement activities. Common uses of QR Codes in India are (a) Ticketing; PNR number or booking Ids are usually lengthy and to make authentication a quick process, QR Code is added to the ticket. BookMyShow, a popular movie ticket booking app, IRCTC, India's train ticket booking portal also adds a QR Code to its Passbook tickets and e-tickets respectively. (b) Newspaper advertisements; with the growing importance of smartphones, QR Codes connect readers from the print ad to dynamic online media. (c) Newspaper Articles; The Times of India, one of India's leading English newspaper, started using QR Codes to connect readers from small piece of information in the paper to full-length articles online. (d) Identification and Authentication of Aadhar card also has a QR Code on it. It stores the information of the ID holder including Name, Aadhar No, Father's name, Date of Birth, Address etc.; this will allow businesses to quickly authenticate user's data by scanning the QR Code on the card. Whatsapp, the most popular messaging app in India has Whatsapp Web that is accessible only by scanning a QR 
Code. When it comes to authenticity, Consumer Electronic product companies use QR Codes on their packaging to allow buyers to verify the authenticity of their products. (e) Payments; the State Bank of India's Anywhere App allows account holders to transfer money. Using an app, a QR Code will be generated. The recipient of the money simply needs to scan the QR Code using app to receive the money. (f) Mobile app downloads; Using a QR Code, brands can redirect customers to App Store pages to get them to download the brand's mobile application. Brands such as Samsung, AirAsia, Gaana, Globus, and HDFC are using such QR Codes in India. (g) Product packaging; to redirect users to additional information or promotional offer. Brands such as Del Monte, Godrej, Amul, Dabur and Tata Tea have adopted this marketing technique to engage consumer. (h) Inventory management; codes are extensively used in transportation and management of product and product cartons.

\section{Review of Literature and Research Design}

In the past years, the mobile phone has gained more and more importance in the everyday life of consumers therefore making it the easiest way for marketers to communicate with. Certainly, these advances have drawn attention from both researchers and marketers about various types of mobile phone based marketing tactics (Wohlfahrt (2002); Trappey and Woodside (2005); Davis and Sajtos (2008)). This mobile platform offers diverse modes, matching desired communication like Short Message Service (SMS), Multimedia Messaging Service (MMS), Mobile Videos, Wireless Access Protocol (WAP) etc., (Beschizza, (2009)). Even the specific characteristics of the mobile phone like geo-targeting ability, ubiquity, immediacy, measurability and interactivity support the application of mobile phones in marketing communication ((Bauer et al., (2005)). Certainly, these advances have drawn attention from both researchers and marketers about various types of mobile phone based marketing tactics (Wohlfahrt (2002); Trappey and Woodside (2005); Davis and Sajtos (2008)). One such marketing tactical tool is the Quick Response Code, generally abbreviated as QR Code. QR Code is a 2 dimensional barcode (data matrix) which is designed to be scanned by a Smartphone camera, in combination with a barcode decoding application (Denso-wave, n.d.). Various such applications are available like QuickMark, Scanlife, RedLaser, i-nigma, QRreader which connect users to some specific e-content like a website, an email address, e-coupons, SMS, a registration form etc. (Handley (2012); Bisel (2011)). QR Codes were first conceptualized by Denso Wave, a Toyota subsidiary in Japan in 1994. Normal barcodes had information stored in only one dimension (horizontally) and were seriously limited in the amount of data they could contain. Denso Wave developed this QR Code as a way of holding information in two dimensions (horizontally and vertically); hence a QR Code was able to accumulate 10 times more information than a normal barcode (Denso-wave, n.d.). Further, QR Codes supported quick and convenient tracking of vehicles, as they can be scanned at very high speed with great ease (Okazaki et al., (2012). Perhaps the most beneficial attribute of QR Codes is their interactive capabilities. According to Patel (2012), with the click of a button on a Smartphone, the QR Code allows consumers to interact with the ad they were viewing in a completely different form of media than was presented to them and the ad which previously possessed only visual and tactile functions, becomes digital and interactive in a matter of seconds.

Further, according to Bisel (2011), QR Codes are simply an image; they can be printed on any surface like newspapers, billboards, product packaging, leaflets and even on the product itself. These monochrome codes can easily to be transformed into "designer" QR code by adding colours and putting the brand name and/or the logo in the forefront of the code image (Podfigurny (2011)). Finally at their best, QR Codes can bridge the online and offline worlds as a QR Code provides the possibility of integrating online content say a website and offline content say a newspaper ad. Due to this characteristic, the QR Code supports the execution of multichannel marketing very effectively (Handley (2012)).

Another interesting attribute of the QR Code is the error correction capability which means that data can be restored even if a QR Code is damaged up to 30\%. QR Codes also offer great versatility to marketers as they can be enlarged to the size of a billboard or minimized to the size of a stamp (QRCodedotcom, 2011). Moreover, QR Codes enable marketers to track the number of scans on each code and identify which medium the scan came from. This feature is certainly a great aid to marketers in measuring intensive consumer activity and analyzing the effectiveness of various advertising mediums Patel (2012).

Today one of the most ubiquitous trends in marketing is the use of QR Codes especially in Japan, USA and Western Europe. Further, with the increasing adoption of Smartphones (almost all have bar code scanning capability); they are rapidly gaining in popularity across Asia especially in India, Korea and Indonesia (Pola (2012); Kent (2012)). QR Codes are open as Denso Wave have not patented them, which means that tools to generate and scan-decode QR Codes are freely available. This enables marketers to easily implement their campaigns and to support consumers to scan the codes used in those campaigns (Matt (2011a)). All the above benefits prove that the QR Code can significantly enhance the return on marketing investment Podfigurny (2011). 
QR Codes are not free of disadvantages. One disadvantage is that using QR Codes, only Smartphone users can be targeted as mobile camera and internet connection is a prerequisite (eHow (2012); Matt (2011b)). But, the real limitation of the QR Code is the lack of offline ability to authenticate source/sponsor of code. Many critics opine that the QR Code itself is very powerful and cost effective; but for marketers it is still a trouble child. Marketers do not seem to have clear objectives thus failing to drive customer engagement through QR Codes (Jason (2011); Handley (2012); Kats (2012)). For example, a QR Code scan simply lead to the homepage of a website which is not optimized for mobile phones or QR Codes are placed in inappropriate places such as on billboards on a speedy highway. Further, the level of awareness of QR Codes among consumers is another problem area - how to get a scanner, how to scan a code, what to expect from a code scan (O'Reilly (2011); Cummings (2011)).

The objective of the above literature study is to identify, at a macro level and micro level the drivers of QR Code. The review of literature on this domain, thus throws light on facts relating to the gap in the study of this subject. (i) The study of QR code focuses the conceptual issues; and (ii) the companies have taken up research in QR Codes independently to suit their needs; (iii) however, very little is known or experimented from customer's point of view to find out the role of advertisements and informal sources such as friends and family members and their influence. This study focuses on identifying such sources. A very few research studies have focused on the nature of QR Codes exhibited in this domain. A few researches have been noticed recently in Indian journals. Most of those studies have looked at the technical and conceptual aspects of it. Therefore the current study focus on the empirical survey of QR Code

The study is exploratory in nature as it endeavors to uncover the latent behavioral respondents in Bangalore. As the study involved covering the respondents from several parts of Bangalore, the study has to be executed in phases.

The universe of the study helped the researcher create the sample. The study covered selected malls in Bangalore city.

\section{Primary Data Source}

First-hand information was obtained from the respondents through structured questionnaire. An interview schedule was constructed to elicit information from the respondents. The researcher chose an interview schedule since the respondent has to be coaxed to answer the questions put forth in the questionnaire. Moreover the researcher had a stringent requirement for the data to be pure and in all senses comprehend the very spirit of the questionnaire and thus the research. The researcher could also clarify any doubts to the respondent and explain the objective of each question whenever the respondent raised doubts.

The validity of the questionnaire was adjudged using Cronbach's coefficient $(\alpha)$ was calculated to test the reliability and internal consistency of the responses. Cronbach's coefficient, having a value of more than 0.7 is considered adequate for such exploratory work. The values of $\alpha$ in this study for the three reported questions were found to be $0.736,0.805$ and 0.765 , giving an average value of 0.768 . It implies that there is a high degree of internal consistency in the responses to the questionnaire.

\section{Sample Size}

The researcher has arrived at a sample size of 210 respondents from various malls in Bangalore based on the following formula:

$$
\mathrm{n}=\mathrm{Z} 2 \times(\mathrm{p}) \times(1-\mathrm{p})
$$

(ME) 2

\section{Objectives of the study}

The main objectives of the study are as follows:

1. To study the awareness of the QR Code in Bangalore

2. To study the usage patterns of QR Code by the respondents

3. To understand the sources of knowledge of QR Codes by the respondents

4. To assess the ease of use of QR code technology by the respondents

\section{Hypothesis of the study}

H0: There is no significant difference between the Gender of the respondents and awareness of the QR Codes

H1: There is a significant difference between the Gender of the respondents and awareness of the QR Codes

H0: There is no significant difference between the age of the respondents and usage pattern of the QR Codes

H1: There is a significant difference between the age of the respondents and usage pattern of the QR Codes

H0: There is no significant difference between the Gender of the respondents and the media vehicle for the awareness of QR Code

H1: There is a significant difference between the Gender of the respondents and the media vehicle for the awareness of QR Code 
H0: There is no significant difference between the education level of the respondents and the purpose of usage of QR code

H1: There is a significant difference between the education level of the respondents and the purpose of usage of QR code

H0: There is no significant difference between the education level of the respondents and the Comfortability in scanning the QR code

H1: There is a significant difference between the education level of the respondents and the Comfortability in scanning the QR code

H0: There is no significant difference between the education level of the respondents and the difficulties in scanning the QR code

H1: There is a significant difference between the education level of the respondents and the difficulties in scanning the QR code

\section{Plan of analysis}

The data collected is initially organized in a meaningful manner with the help of SPSS software. Once organized, the researcher tabulated the frequencies, which provided the requisite profile of the data collected and help the researcher build the contingency tables for further detailed analysis. On performing detailed analysis, patterns from the data is further put for validation through testing of hypothesis, where ever the researcher deemed important and based on the conditions set for such test.

\section{Data Analysis and Interpretation}

Table No 3.1Table showing the age of the respondents

\begin{tabular}{|l|l|l|}
\hline Gender & No of respondents & Percentage \\
\hline Male & 104 & 49.5 \\
\hline Female & 106 & 50.5 \\
\hline Total & 210 & 100 \\
\hline
\end{tabular}

Source: Field investigation

It is evident from the above table no 3.1 that the 50.5 percent of the respondents were female and 49.5 percent of the respondents were male

Table No 3.2 Table showing the age of the respondents

\begin{tabular}{|l|l|l|}
\hline Age & No of respondents & Percentage \\
\hline Below 20 years & 49 & 23 \\
\hline $21-35$ & 65 & 31 \\
\hline $36-50$ & 72 & 34 \\
\hline 51 and above & 24 & 12 \\
\hline Total & 210 & 100 \\
\hline
\end{tabular}

Source: Field investigation

It is evident from the above table no 3.2 that the 34 percent of the respondents belong to age group 3650 followed by 31 percent belong to $21-35,23$ percent of the respondents below 20 years and balance belong to 51 and above

Table No 3.3 Table Showing the Qualification of the Respondents

\begin{tabular}{|c|c|c|}
\hline Qualification & No of respondents & Percentage \\
\hline Undergraduate & 40 & 19.0 \\
\hline Graduate & 42 & 20.0 \\
\hline Postgraduate & 62 & 29.5 \\
\hline Professional & 66 & 31.4 \\
\hline Total & 210 & 100 \\
\hline
\end{tabular}

Source: Field investigation

It is evident from the above table no 3.3 that the 31.4 percent of the respondents were professionals followed by 29.5 percent were post graduates, another 20 percent belong to graduate category and rest 19 percent were undergraduates

Table No 3.4 Table Showing the Occupation of the Respondents

\begin{tabular}{|l|l|l|}
\hline Occupation & No of respondents & Percentage \\
\hline Student & 22 & 10.5 \\
\hline Professional & 43 & 20.5 \\
\hline Employee & 62 & 29.5 \\
\hline
\end{tabular}


Driving Online Traffic by Using QR (Quick Response) Code

\begin{tabular}{|l|l|l|}
\hline Self employed & 63 & 30.0 \\
\hline House wife & 20 & 9.5 \\
\hline Total & 210 & 100 \\
\hline
\end{tabular}

Source: Field investigation

It is evident from the above table no 3.4 that the 30 percent of the respondents were self-employed, followed by 29.5 percent were salaried, another 20.5 percent belong to professional category, 10.5 percent are students and rest 9.5 percent were house wives.

Table No. 3.5 Table Showing the Familiarity of the Respondents towards QR Codes

\begin{tabular}{|l|l|c|}
\hline & No of respondents & Percentage \\
\hline Not at all familiar & 24 & 11.4 \\
\hline Not familiar & 25 & 11.9 \\
\hline Indifferent & 26 & 12.4 \\
\hline Familiar & 76 & 36.2 \\
\hline Very much familiar & 59 & 28.1 \\
\hline Total & 210 & 100 \\
\hline
\end{tabular}

Source: Field investigation

It is evident from the above table no 3.5 that 36.2 percent of the respondents were familiar with QR Code, followed by 28.1 percent very much familiar, 12.4 percent knows about it but not sure about the way it functions and 11.9 and 11.4 percent were not aware of this QR Code

Cross tabulation of Gender and familiar with QR codes

\begin{tabular}{|c|c|c|c|c|c|c|c|}
\hline & \multicolumn{5}{|c|}{ Are you familiar with QR codes } & \multirow[t]{2}{*}{ Total } \\
\hline & & Not at all familiar & Not familiar & Indifferent & Familiar & Very much familiar & \\
\hline \multirow[t]{2}{*}{ Gender } & Male & 8 & 9 & 9 & 50 & 28 & 104 \\
\hline & Female & 16 & 16 & 17 & 26 & 31 & 106 \\
\hline & Total & 24 & 25 & 26 & 76 & 59 & 210 \\
\hline
\end{tabular}

The Pearson Chi square has been utilized to assess the relationship between the gender of the respondents and the familiarity of QR Code and the following hypothesis has been framed.

H0: There is no significant difference between the Gender of the respondents and awareness of the QR Codes H1: There is significant difference between the Gender of the respondents and awareness of the QR Codes

Table showing Chi Square Results

\begin{tabular}{|l|l|c|c|}
\hline & Value & df & Asymp. Sig. (2-sided) \\
\hline Pearson Chi-Square & $14.802^{\mathrm{a}}$ & 4 & .005 \\
\hline Likelihood Ratio & 15.051 & 4 & .005 \\
\hline Linear-by-Linear Association & 4.868 & 1 & .027 \\
\hline N of Valid Cases & 210 & & \\
\hline
\end{tabular}

It is evident from the above table that the Chi-Square value was 14.802 with 4 degrees of freedom and with a $\mathrm{p}$ value of 0.005 . Since it was lesser than the set level of 5 percent we can reject the Null hypothesis.

Table No 3.6 Table Showing the Recognition of the QR Codes By Respondents

\begin{tabular}{|c|l|l|}
\hline & No of respondents & Percentage \\
\hline Yes & 136 & 64.8 \\
\hline No & 74 & 35.2 \\
\hline Total & 210 & 100 \\
\hline
\end{tabular}

Source: Field investigation

It is evident from the above table that 64.8 percent or the respondents were able to recognise the QR code without any aids. However, balance 35.2 percent were unable to recognise the QR Code without any aid.

Table No 3.7 Table Showing Application of QR Code Scanner Inrespondent's Mobile

Source: Field investigation

\begin{tabular}{|l|l|l|}
\hline & No of respondents & Percentage \\
\hline Yes & 89 & 42.4 \\
\hline No & 121 & 57.6 \\
\hline Total & 210 & 100 \\
\hline
\end{tabular}

It is evident from the above table that 57.6 percent of the respondents had no QR code scanner on their mobile. However, balance 42.4 percent had QR code scanner on their mobile 
Table No 3.8 Table Showing the Usage of Scanner Application Usage Pattern by the Respondents

\begin{tabular}{|l|l|l|}
\hline & No of respondents & Percentage \\
\hline Not at all & 103 & 49.0 \\
\hline Rarely & 18 & 8.6 \\
\hline Sometimes & 59 & 28.1 \\
\hline Always & 30 & 14.3 \\
\hline Total & 210 & 100 \\
\hline
\end{tabular}

Source: Field investigation

It is evident from the above table that 49.0 percent of the respondents were not at all using scanner apps. However, 28.1 percent of the respondents use it sometimes followed by 14.3 always.

Table No 3.9 Table showing Source of Knowledge about QR Code

\begin{tabular}{|c|c|c|}
\hline & No of respondents & Percentage \\
\hline Friends and relatives & 37 & 17.6 \\
\hline Advertisements & 116 & 55.2 \\
\hline Retailers & 41 & 19.5 \\
\hline Others please specify & 16 & 7.6 \\
\hline Total & 210 & 100 \\
\hline
\end{tabular}

Source: Field investigation

It is evident from the above table that 55.2 percent of the respondents came to know about QR code through advertisements. However, 19.5 percent through retailers followed by 17.6 percent through friends and relatives.

Table No 3.10 Table showing ad source through which respondents got knowledge about QR Code

\begin{tabular}{|l|c|c|}
\hline & No of respondents & Percentage \\
\hline Print media & 92 & 42.39 \\
\hline Broadcast media & 12 & 5.53 \\
\hline Hoardings & 15 & 6.91 \\
\hline Mobile ads & 32 & 14.74 \\
\hline Websites & 64 & 29.49 \\
\hline Direct mailing & 06 & 2.76 \\
\hline Others please specify & 06 & 2.76 \\
\hline Total & 217 & 100 \\
\hline
\end{tabular}

Source: Field investigation

It is evident from the above table that 42.39 percent of the respondents came to know about QR code through Print media ads. However, 29.4 percent came to know about it through websites followed by 14.74 percent through mobile ads

The Pearson Chi square has been utilized to assess the relationship between the gender of the respondents and the media vehicle for the awareness of QR Code and the following hypothesis has been framed. H0: There is no significant difference between the Gender of the respondents and the media vehicle for the awareness of QR Code

H1: There is a significant difference between the Gender of the respondents and the media vehicle for the awareness of QR Code

Table showing Chi Square results

\begin{tabular}{|l|l|l|c|}
\hline & Value & df & Asymp. Sig. (2-sided) \\
\hline Pearson Chi-Square & $20.602^{\mathrm{a}}$ & 6 & .002 \\
\hline Likelihood Ratio & 23.955 & 6 & .001 \\
\hline Linear-by-Linear Association & 2.026 & 1 & .155 \\
\hline N of Valid Cases & 217 & & \\
\hline
\end{tabular}

It is evident from the above table that the Chi-Square value was 20.602 with 6 degrees of freedom and with a $\mathrm{p}$ value of 0.002 . Since it was lesser than the set level of 5 percent we can reject the Null hypothesis.

Table No 3.11 Table Showing the Respondents Who Can Recall Ads from Print Media Having QR Codes

\begin{tabular}{|l|l|l|}
\hline & No of respondents & Percentage \\
\hline Yes & 89 & 55.28 \\
\hline No & 72 & 44.72 \\
\hline Total & 161 & 100 \\
\hline
\end{tabular}

Source: Field investigation 
It is evident from the above table that 55.28 percent of the respondents were able to recall the print media ads and balance were not able to recall the ads.

Table No 3.12 Table Showing Necessity of Scanning QR Codes

\begin{tabular}{|l|l|l|}
\hline & No of respondents & Percentage \\
\hline Not at all & 32 & 15.2 \\
\hline Unnecessary & 22 & 10.5 \\
\hline Indifferent & 20 & 9.5 \\
\hline Necessary & 78 & 37.1 \\
\hline Very much necessary & 58 & 27.6 \\
\hline Total & 210 & 100 \\
\hline
\end{tabular}

Source: Field investigation

It is evident from the above table that 37. 1 percent of the respondents were found QR codes are necessary. However, 27.6 percent of the respondents felt that it was very much necessary and 15.2 percent felt that it was not at all necessary.

Table No 3.13 Table Showing Purpose of Scanning QR Codes

\begin{tabular}{|l|c|c|}
\hline & No of respondents & Percentage \\
\hline To redeem coupons & 46 & 15.13 \\
\hline To avail discounts & 45 & 14.80 \\
\hline To avail sales offer & 61 & 20.06 \\
\hline To get more information about the company products and events & 16 & 5.26 \\
\hline To share app with others & 24 & 7.89 \\
\hline To get access to exclusive content & 40 & 13.16 \\
\hline For regular purchase & 61 & 20.06 \\
\hline I did nothing with it & 11 & 3.61 \\
\hline Total & 304 & 100 \\
\hline
\end{tabular}

Source: Field investigation

Majority of the respondents (20.06 percent) uses QR code for regular purchases. However, 20.06 percent use this to avail sales offer followed by 15.13 percent to redeem coupons, 14.80 to avail discounts. But, 3.61 percent of the respondents did nothing with it.

The Pearson Chi square has been utilized to assess the relationship between the education level of the respondents and the purpose of usage of QR code and the following hypothesis has been framed.

H0: There is no significant difference between the education level of the respondents and the purpose of usage of QR code

H1: There is a significant difference between the education level of the respondents and the purpose of usage of QR code

Table Showing Chi Square Results

\begin{tabular}{|l|l|l|c|}
\hline & Value & df & Asymp. Sig. (2-sided) \\
\hline Pearson Chi-Square & $68.555^{\text {a }}$ & 21 & .000 \\
\hline Likelihood Ratio & 85.540 & 21 & .000 \\
\hline Linear-by-Linear Association & .626 & 1 & .429 \\
\hline N of Valid Cases & 304 & & \\
\hline
\end{tabular}

It is evident from the above table that the Chi-Square value was 68.555 with 21 degrees of freedom and with a $\mathrm{p}$ value of 0.000 . Since it was lesser than the set level of 5 percent we can reject the Null hypothesis.

Table No 3.14 Table showing Comfortability in scanning QR Codes

\begin{tabular}{|c|c|c|}
\hline & No of respondents & Percentage \\
\hline Very difficult & 49 & 30.43 \\
\hline Difficult & 14 & 8.70 \\
\hline Indifferent & 43 & 26.71 \\
\hline Easy & 41 & 25.47 \\
\hline Very easy & 14 & 8.70 \\
\hline Total & 161 & 100 \\
\hline
\end{tabular}

Source: Field investigation

25.47 percentage of the respondents felt it is easy to use QR codes and 8.70 percent claimed it was very easy to use. However 26.71 percent felt indifferent followed by 30.43 percent felt it was very difficult to use QR code. 
The Pearson Chi square has been utilized to assess the relationship between the education level of the respondents and the Comfortability in scanning the QR code and the following hypothesis has been framed.

H0: There is no significant difference between the education level of the respondents and the Comfortability in scanning the QR code

H1: There is a significant difference between the education level of the respondents and the Comfortability in scanning the QR code

Table Showing Chi Square Results

\begin{tabular}{|l|l|l|c|}
\hline & Value & df & Asymp. Sig. (2-sided) \\
\hline Pearson Chi-Square & $43.993^{\mathrm{a}}$ & 12 & .000 \\
\hline Likelihood Ratio & 49.479 & 12 & .000 \\
\hline Linear-by-Linear Association & 4.059 & 1 & .044 \\
\hline N of Valid Cases & 161 & & \\
\hline
\end{tabular}

It is evident from the above table that the Chi-Square value was 43.993 with 12 degrees of freedom and with a $\mathrm{p}$ value of 0.000 . Since it was lesser than the set level of 5 percent we can reject the Null hypothesis.

Table No 3.15 Table Showing Difficulties While Scanning QR Codes

\begin{tabular}{|l|c|c|}
\hline & No of respondents & Percentage \\
\hline Not user friendly & 33 & 20.50 \\
\hline Waste of time & 36 & 22.36 \\
\hline Complicated technology & 41 & 25.47 \\
\hline Locating the app to scan & 47 & 29.19 \\
\hline Others please specify & 4 & 2.48 \\
\hline Total & 161 & 100 \\
\hline
\end{tabular}

Source: Field investigation

Majority of the respondents (29.19 percent) found that locating the app to scan was the most difficult task. However, 25.47 felt that complicated technology is the major barrier for its usage followed by 22.36 percent felt it was a waste of time and balance 20.50 felt it was not user friendly.

The Pearson Chi square has been utilized to assess the relationship between education level of the respondents and the difficulties in scanning the QR code and the following hypothesis has been framed.

H0: There is no significant difference between the education level of the respondents and the difficulties in scanning the QR code

H1: There is a significant difference between the education level of the respondents and the difficulties in scanning the QR code

Table Showing Chi Square Results

\begin{tabular}{|l|l|l|c|}
\hline & Value & df & Asymp. Sig. (2-sided) \\
\hline Pearson Chi-Square & $43.225^{\text {a }}$ & 12 & .000 \\
\hline Likelihood Ratio & 46.530 & 12 & .000 \\
\hline Linear-by-Linear Association & 3.724 & 1 & .054 \\
\hline No of Valid Cases & 161 & & \\
\hline
\end{tabular}

It is evident from the above table that the Chi-Square value was 43.225 with 12 degrees of freedom and with a $\mathrm{p}$ value of 0.000 . Since it was lesser than the set level of 5 percent we can reject the Null hypothesis.

Table No 3.16 Table Showing Respondents Who Share Usefulness Of This App

\begin{tabular}{|l|c|c|}
\hline & No of respondents & Percentage \\
\hline Not at all useful & 38 & 23.60 \\
\hline Not useful & 34 & 21.11 \\
\hline Indifferent & 35 & 21.74 \\
\hline Useful & 11 & 6.83 \\
\hline Very much useful & 43 & 26.71 \\
\hline Total & 161 & 100 \\
\hline
\end{tabular}

Source: Field investigation

Majority of the respondents (26.71 percent) found that QR codes are very much useful for them. However, 23.60 felt it is not at all useful followed by 21.74 were indifferent and 21.11 percent claim it's not useful. 


\section{Summary of Findings}

$>49.5 \%$ of the respondents were male and $50.5 \%$ were female.

$>34 \%$ of the respondents belong to the age group of $36-50$ years and $31 \%$ of the respondents belong to age group of 21-35 years.

$>$ Sample population revealed that $31.4 \%$ of the respondents were professionals and $29.5 \%$ were post graduates. It indicates that the majority of the respondents were highly qualified. It is observed that $30 \%$ of the respondents were self-employed and $29.5 \%$ of the respondents were employees.

$>\quad 36.2 \%$ of the respondents were being familiar with QR Codes. However, $28.1 \%$ being very much familiar with QR codes i.e., totally $64.3 \%$ of the respondents were familiar with QR codes.

$>64.8 \%$ of the respondents recognized QR Codes, whereas $35.2 \%$ of the respondents did not.

$>57.6 \%$ of the respondents did not have QR Code scanner app on their mobile, whereas $42.4 \%$ of the respondents have scanner app on their mobile.

$>$ Even after having code scanner app on their mobiles, $49 \%$ of the respondents did not use at all, whereas $28.1 \%$ of the respondents use the app sometimes.

$>$ Study revealed that $55.2 \%$ of the respondents came to know about the app through advertisements and the rest, through friends, relatives and retailers.

$>$ It is through print media that $42.39 \%$ of the respondents got to know about QR Codes through print media. However, $29.49 \%$ of the respondents came to know through websites and $14.74 \%$ through Mobile apps.

$>$ When it comes to recalling of ads having QR codes through print media, $55.28 \%$ of the respondents were able to recall the ads. However, the rest of the respondents were unable to recall the ad.

$>$ There is a necessity for scanning QR Codes, says $64.7 \%(37.1 \%+27.6 \%)$ of the respondents. Out of them only $20.06 \%$ of the respondents use QR codes to avail sales offer and for regular purchases respectively. However, $15.13 \%$ of them use it to redeem coupons and 14.80 percent of them use it to avail discounts.

$>25.47 \%$ and $8.7 \%$ of the respondents found it easy to use QR codes. However, 30.43\% found it very difficult to use QR codes.

$>$ Even though majority of the respondents are familiar with scanner app, yet $29.19 \%$ of the respondents are still finding difficulty in locating the app to scan, followed by $25.47 \%$ who found the difficulty in understating the technical aspect of the QR codes. 22.36\% of the respondents felt it was wasting of time to scan QR codes. $20.5 \%$ of the respondents felt that the technology were not user friendly.

$>$ Irrespective of finding difficulty in locating app to scan the QR Codes, 33.54\% (26.71\% of the respondents and $6.83 \%$ of the respondents) agreed to share the usefulness of the app.

$>$ There is significant difference between the Gender of the respondents and awareness of the QR Codes.

$>$ There is a significant difference between the Gender of the respondents and the media vehicle for the awareness of QR Code.

$>$ There is a significant difference between the education level of the respondents and the purpose of usage of QR code.

$>$ There is a significant difference between the education level of the respondents and the Comfortability in scanning the QR code.

$>$ There is a significant difference between the education level of the respondents and the difficulties in scanning the QR code.

\section{Discussion and Conclusion}

QR code is a matrix code, which was first devised by Denso Wave in Japan in 1994 for the Toyota subsidiary. The QR Code system has been accepted outside the automobile industry due to its rapid readability and higher storage capacity compared to conventional UPC barcodes. They have become more popular because of their rapid speed; accuracy and their convenience have been accepted universally. The industry began to call for unique codes which are capable of handling more information, more character types, and that could be printed in a smaller arena. The aim of the current paper was to study the consumer's acceptance and understanding of the technology involved in QR code system.

The study revealed that only $36.2 \%$ being familiar and $28.1 \%$ being very much familiar and only $64.8 \%$ of the respondents recognized QR Codes, whereas $35.2 \%$ of the respondents did not. As Majority of the respondents do not have QR Code scanner app in their mobile, the marketers should promote more app solutions to address this issue. Out of those who are having AQ code mobile app majority of them are not using QR code app. Most of the customers came to know about QR code through advertisements and friends and relatives, therefore it is recommended to the marketers to exploit this particular medium especially opinion leaders for diffusion of innovation. QR Codes undoubtedly bring benefits to both consumers and marketers, with its technological capability to quickly provide more information to a consumer who is interested in the company or brand therefore it is recommend to the service providers to make use of various media options to reach the consumers to use this technology. Most of the respondents were unable to recall the QR code ads including 
professionals and younger generation respondents therefore it is recommended to develop guerrilla marketing strategies in malls for creating awareness and recalling of advertisements. With respect to recall of print media having QR Codes, the respondents were 55.28\% and the rest did not recall. Majority of the respondents found it very difficult to understand the technology and only few of them find it easy and comfortable in scanning QR Codes. Even though majority of the respondents are familiar with scanner app, most of them are still finding difficulty in locating the app to scan. Irrespective of finding difficulty in locating app to scan the QR Codes, agreed to share the usefulness of the app. The above study revealed that appeal of QR codes to marketers is clear and even the consumers have accepted it. Patel (2012) is of the opinion that QR codes are easy to create and implementing a QR code into an advertisement is far less expensive than a company having to develop its own smartphone app. Even Guluk (2012) of the opinion that marketers find value in QR codes because they can be placed just about anywhere. Though People had enough time and a reason to take out their smartphone to scan the QR code, however, majority of them were unable to use it because of the technology being not user friendly. Apart from this, QR codes offer yet another important solution to the marketers. The QR code has the capacity to measure consumer purchase activity, and can track the number of scans on each code and recognize the medium through which the scans are made. Example: newspaper, magazine etc. This aspect of QR code will assist the marketers to identify the medium in which they want to place advertisements. In an organized retail sector, QR codes can be placed on signs within the store directing customers to a checkout, restroom, or specific isle for the product for which they are looking. When shoppers have the opportunity to access this kind of information on their own, it frees up salespeople on the sales floor and can increase productivity Patel (2012). Because of QR codes consumers can transact business across the globe just by pressing a button on a smartphone.

This current paper concludes that there are so many possibilities for QR code's applications in different domains that are yet to be explored, now only a few marketers are using this QR codes for their interest. The underlying conclusion that should be taken and drawn out of this current study is that engaging consumers through the use of QR codes is about both context and action and survey findings very clearly points it out that $\mathrm{QR}$ codes have no demographic barriers when it comes to adaption of new technology but only concern is ease of use and awareness. With the correct context and scenario, there is great potential for the future of the QR code as they provide greater flexibility. As the market stands today, it is both viable and practicable to project that future QR codes containing point-of-purchase capabilities and value-added money-making purposes will soon become pervasive. Apart from this, QR code opens up a platform for researchers to probe the possibilities to boost the performance of QR code or to blend QR code with different applications and making it much more user-friendly.

\section{References}

[1] Bauer, H.H., Reichardt, T., Barnes, S.J. and Neumann, N.M. (2005), "Driving Consumer Acceptance of Mobile Marketing: A Theoretical Framework and Empirical Study", Journal of Electronic Commerce Research, Vol. 6, pp. 181-192

[2] Beschizza, F. (2009), "Managing Mobile Marketing and Advertising Campaigns", COI,

[3] Bisel, J. (2011), "Mobile Marketing and QR Codes", Hudson Valley Business Journal, September Issue, p. 21

[4] Cummings, S. (2011), "Why the QR code is Failing", iMedia, [online] at: www.imediaconnection. com/content/30267.asp (accessed January 12, 2012)

[5] Daniells, K. (2011), “The Rise of QR Codes", Infographic, [online] at:

[6] www.digitalbuzzblog.com/infographic-the-rise-of-qr-codes (accessed January 2, 2012)

[7] Davis, R. and Sajtos, L. (2008), "Measuring Consumer Interactivity in Response to Campaigns Coupling Mobile and Television Media", Journal of Advertising Research, Vol. 48, No. 3, pp. 375-391

[8] Denso-wave (n.d.), "QR Codes", [online] at: http://www.denso-wave.com/qrcode/aboutqre. html (accessed February 14, 2011)

[9] eHow (2012), "Disadvantages of Quick Response Bar Code" [online] at: www.ehow.com/ list_7365813_disadvantages-quickresponse-bar-code.html (accessed December 19, 2012)

[10] Handley, A. (2012), "Cracking the Mobile Code", Entrepreneur, Feb 2012 Issue, pp. 56-57 IRS Q4 2011 Report (2011), "Indian Readership Survey”, [online] at: http://mruc. net/irs2011q4 \%20toplines.pdf (accessed October 29, 2012)

[11] Jason, A. (2011), "New Wine in New Bottles", Entrepreneur, Issue Oct 2011, pp. 42-43

[12] Kats, Rimma. (2012), "How to Create an Effective QR Code Campaign", Mobile Marketer, [online] at: http://www.mobilemarketer.com/cms/news/software-technology/13452 .html (accessed August 6, 2012)

[13] Kent, A. (2012), "Smartphone and Mobile Marketing: Key Lessons", NZB, March 2012 Issue, p. 60

[14] Matt, B. (2011a), "10 Reasons QR Codes Will Be Absolutely Everywhere", [online] at:

[15] www.notixtech.com/blog/10-reasons-qr-codes-will-be-absolutely-everywhere (accessed October 23, 2011)

[16] Matt, B. (2011b), "Microsoft Tag, JagTag, and QR Codes Compared", [online] at: www.notixtech.com/blog/microsoft-tag,-jagtag,and-qr-codes-compared (accessed December 25, 2012

[17] MobiThinking (2012), "Global Mobile Statistics-2012”, [online] at: http://mobithinking. com/mobile-marketing-tools/latest-mobilestats/a\#subscribers (accessed July 07, 2012)

[18] Okazaki, S., Li, H. and Hirose, M. (2012), "Benchmarking the Use of QR Code in Mobile Promotion”, Journal of Advertising Research, Vol. 52, No. 1, pp. 102-117

[19] Ollig, M. (2011), "Internet URL address-shortening services are useful”, Bits \& Bytes Column, January 21, 2011

[20] O'Reilly, L. (2011), "Most People have no Idea of what QR Codes are for", Marketing Week, p. 4

[21] Patel, K. (2012), "Marketer Love for QR Codes Not Shared by Consumers", Advertising Age,[online] at: http://adage.com/article/digital/marketer-love-qr-codes-shared-consumers/231854 (accessed July 14, 2012) 
[22] Podfigurny, R. (2011), "Enhancing Your Marketing with QR Codes \& Smart-Phone Technology", The Central New York Business Journal, pp. 15

[23] Pola, S. (2012), "From Madison St. to Mumbai: Quick Response (QR) Codes Conquer the World", INGurus, [online] at: www.ingurus.com/from-madison-st-to-mumbai-quickresponse- qr-codes conquer-the-world/ (accessed February 26, 2012)

[24] Poon, C. (2011), "QR Codes Link the Offline with the Online", Straight

[25] QRCodedotcom. (2011), "QR Code Features", [online] at: http://www.qrcode.com/en /qrfeature.html (accessed December 28, 2011)

[26] Tolliver, W.H. (2011), "Making Best Use of QR Codes: Gleaning Lessons from the Latest Data", The Seybold Report, Vol. 11, No. 23, pp. 2-7

[27] Trappey, R.J. and Woodside, A.G. (2005), “Consumer Responses to Interactive Advertising Campaigns Coupling Short Message Service, Direct Marketing and TV Commercials", Journal of Advertising Research, Vol. 45, pp. 382-401

[28] Wohlfahrt, J. (2002), "Wireless Advertising", In: Wohlfarth, J. and Thorsten, W. (eds.), Mobile Commerce: Grundlagen, Geschäftsmodelle, Erfolgsfaktoren, GüntherSilbere, Wiesbaden, Press. 